\title{
A Compra do Latão: um diálogo sobre a arte de conhecer
}

\author{
Thereza de Jesus Santos Junqueira \\ Universidade Federal da Bahia - UFBA \\ Email: therezajunqueira@yahoo.com.br
}

"A compra do latão", de Bertolt Brecht, é um texto limite entre arte dramática e teoria. Pode-se dizer que a peça, ao "representar" as "realidades" do fazer teatral, apresenta, sugestiva e exemplarmente, a habilidade da arte em promover conhecimento, destacando ainda o saber diferenciado que propicia. Não se está a observar o cotidiano do teatro, mas uma apresentação desse cotidiano; não temos um observador que nos relata o que vê, mas sim personagens que falam a partir dos lugares (pontos de vista) construídos para elas. Em seu diálogo teatral, Brecht propõe um diálogo filosófico.

Palavras-chave

Arte Dramática. Teoria. Conhecimento.
Keywords

Dramatic Art. Theory. Knowledge. 
Ao estudar a obra de Brecht percebe-se como era importante, para o autor, iluminar os entendimentos teóricos que subsidiavam seu fazer teatral. Paralelamente à escritura e montagem de suas peças eram registrados, em seus relatos de trabalho, bem como em seus textos teóricos, as teorias criticadas e aquelas deduzidas para orientar sua arte.

Essa inquietação brechtiana pode ser especialmente percebida na peça "A compra do latão", em que personagens conversam sobre o teatro, seus princípios e funções, e sobre como seria possível conseguir melhores reproduções da vida em sociedade. Nesse diálogo, são recuperadas as principais teorias com as quais autor dialoga para construir o que chamou de teatro épico - de Aristóteles às peças e autores naturalistas.

Trata-se de um texto limite entre arte dramática e teoria. Está claro seu propósito dramatúrgico, tendo em vista a sua forma de diálogo, a caracterização das personagens através de suas falas e as rubricas que delimitam o espaço cênico e oferecem orientações para os atores. Mas também está claro seu viés teórico, uma vez que as falas das personagens, recheadas de intertextualidades explícitas e implícitas, refletem sobre temas filosóficos e técnicos acerca do fazer teatral. Em seu diálogo teatral, Brecht propõe um diálogo filosófico.

Nesse trabalho, pretende-se refletir sobre a maneira como Brecht trata a representação, em crítica à matriz aristotélica. Pode-se dizer que a peça, ao "representar" as "realidades" do fazer teatral, apresenta, sugestiva e exemplarmente, a habilidade da arte em promover conhecimento, destacando ainda o saber diferenciado que propicia. Não se está a observar o cotidiano do teatro, mas uma apresentação desse cotidiano; não temos um observador que nos relata o que vê, mas sim personagens que falam a partir dos lugares (pontos de vista) construídos para elas.

\section{Sobre a peça}

"A compra do latão" é uma peça inacabada, escrita ao longo de 16 (dezesseis) anos, entre 1939 e 1955, composta por fragmentos de diálogos, discursos, poemas e peças de exercício, nos quais Brecht coloca em discussão sua proposta de um novo teatro não aristotélico. ${ }^{1}$

A peça conta a história dos participantes de uma companhia de teatro, a saber, um "dramaturgista" (conforme consta da tradução), um ator, uma atriz e o maquinista, que recebem a visita de um filósofo, interessado na prática teatral. A conversa se passa em um palco que está sendo desmontado, e se prolonga durante quatro noites, cada uma compondo um ato.

As falas refletem os diferentes interesses dos participantes e mostram, em seu conjunto, os contornos dos "novos meios da arte dramática". Cada personagem contribui distintamente para sua construção. Não há um posicionamento idealmente correto ou condizente com o teorizar de Brecht. Da crítica do filósofo, que não é completamente aceita, pois acabaria por desnaturar o teatro, acaba surgindo a

10 texto analisado consta de uma edição portuguesa da editora Vega, traduzido por Urs Zuber com a colaboração de Peggy Berndt, publicada em 1999. A peça é apresentada conforme concebida em seu processo criativo, fracionada em quatro fases de trabalho, a primeira de 1939-1941, a segunda de 1942 a 1943, a terceira em 1945, e a quarta de 1948 a 1955. As falas das personagens em cada fase e em cada noite é precedida de anotações esquemáticas do autor, que parecem preparar a escrita, e seguida de textos que não se associam às noites, das peças de exercício, de poemas e dos anexos ao texto. O texto em alemão constante do quinto volume da obra Schriften zum Theater, publicado pela editora Suhrkamp em 1963, serviu de referência e auxiliou a compreender a proposta da edição portuguesa. 
nova maneira de fazer teatro (Hecht, Gellert, 1999, p. 171).

O filósofo deseja utilizar o teatro, que define como a "arte de imitação dos homens", como um meio para a representação ou demonstração plástica de problemas e acontecimentos que necessitam explicação:

FILÓSOFO. Em todas as áreas, a ciência procura possibilidades de experimentação ou de representação plástica dos problemas. Fazem-se modelos que mostram os movimentos dos astros, com aparelhos engenhosos demonstra-se o comportamento dos gases. Experimenta-se também com homens, mas aqui as possibilidades da demonstração são muito limitadas. A minha ideia era então utilizar para tais demonstrações a vossa arte da imitação dos homens. Acontecimentos da vida em comunidade dos homens que necessitam de explicação poderiam ser imitados, de modo que seria possível, face a estas demonstrações plásticas, ganhar certos conhecimentos de utilidade prática (Brecht, 1999, p. 29).

O dramaturgista é um defensor da arte dramática. Mas, embora afaste a iniciativa do filósofo, em favor das peculiaridades do teatro, reconhece possibilidade de fruição artística com sua proposta. Mesmo fazendo arte com fins instrutivos e convidando o espectador a pensar, além de sentir, entende o dramaturgista, convencido, ao final da quarta noite, que a companhia estaria desempenhando uma atividade artística.

DRAMATURGISTA. Estudamos até agora da melhor maneira possível as muitas directivas através das quais queres tornar o teatro tão instrutivo como a ciência. Tinhas-nos convidado a trabalhar no seu teatro, que deveria ser um instituto científico. Fazer arte não deveria ser o nosso objetivo. Mas na verdade tivemos de mobilizar toda a nossa arte para satisfazer os teus desejos. Para falar francamente, representando como queres e com as finalidades que queres, ainda continuamos a fazer arte (Brecht, 1999, p. 61).

$\mathrm{O}$ ator defende a autonomia da arte, que não deveria servir às práticas sociais, é a personagem que enfrenta o filósofo, chegando a discussões conflituosas:

\begin{abstract}
ACTOR. Detesto todas estas conversas sobre a arte como servidora da sociedade. Temos aí a sociedade toda-poderosa, e a arte não faz parte dela, só lhe pertence, é a sua criada de mesa. Temos mesmo de ser todos criados? Não podemos ser todos senhores? A arte não pode ser uma senhora? Acabemos com os criados, também na arte (Brecht, 1999, p. 62).
\end{abstract}

Sobre a atriz e o maquinista pode-se dizer pouco, tendo em vista que são poucas e breves suas aparições. A atriz parece comprometida com um novo teatro, o que pode ser percebido em críticas que menosprezam a arte dramática tradicional.

Os atores representam o que seria uma conversa em uma companhia de teatro e, assim, oferecem um objeto artístico para o espectador, na medida em que este não é um participante daquela conversa cênica, ele experimenta aquela conversa da plateia ou como leitor do texto. Eles não estão meramente conversando, eles estão encenando uma conversa!

A postura que o texto e o espetáculo pedem é inteiramente crítica. Embora o que esteja em discussão sejam questões teóricas a respeito da arte e do fazer teatral, o que lemos são pontos de vista diferentes, cada qual defende e critica aquela arte a partir de seus interesses, de modo que o texto não entrega um conceito acabado que represente o ponto de vista do 
autor. O que se lê são pontos de vista diferentes, em direção à construção de um fazer diferenciado.

\section{Um teatro não aristotélico}

O problema da prática teatral naturalista, de matriz aristotélica, para Brecht, tem a ver com o ilusionismo, pelo qual o espectador é levado passivamente a identificar-se com os personagens e com a cena, crendo que está diante da realidade. $\mathrm{O}$ autor entende que essa postura não é condizente com o homem de sua época, "o homem da época científica", pautado pela atitude crítica. A ilusão impede a atitude crítica por parte do espectador (Brecht, 2005), promovendo um conhecimento falso, impositivo.

A primeira noite de A compra do latão denuncia justamente o ilusionismo, conforme se pode ler na crítica do filósofo ao espetáculo que assistira (Brecht, 1999, p. 23):

DRAMATURGISTA. Parece que aos teus olhos realizamos aqui danças de guerras bárbaras ao serviço de cultos obscuros e obscenos, intrujice, magia, missas negras?

ACTOR. A representação da Nora uma missa negra! A nobre Antígona uma dança de guerra bárbara! A de Hamlet uma intrujice! Estou a gostar disto! FILÓSOFO. Devo ter-vos compreendido mal. Admito.

ACTOR. Profundamente, meu amigo.

FILÓSOFO. Deve ser por ter tomado os vossos discursos a sério, e não me ter apercebido que a vossa maneira de falar era uma brincadeira.

DRAMATURGISTA. Que estás a querer dizer com isso? Qual maneira de falar? FILÓSOFO. De serem 'servidores da palavra', de a vossa arte ser um 'templo', de que o espectador tenha de estar 'cativado', de que haja 'qualquer coisa de divino' nas vossas representações, etc, etc. Pensei mesmo que vocês quisessem manter de pé um culto antigo.

DRAMATURGISTA. Isso são maneiras de falar! Só quer dizer que levamos as coisas a sério.

ACTOR. Isso distingue-nos do teatro comercial. Do divertimento vulgar, etc. FILÓSOFO. Com certeza. Não me teria deixado enganar se não tivesse mesmo visto espectadores 'cativados' nos vossos teatros. Toma a noite de hoje por exemplo! Quando o teu Lear amaldiçoou as filhas, um senhor careca que estava ao meu lado começou a ofegar de maneira tão pouco natural que perguntei porque não começava já a espumar pela boca, ao identificar-se tão completamente com a tua maravilhosa representação da fúria.

ACTRIZ. Ele já teve noites melhores!

Os participantes da companhia, salvo a atriz, sentem-se ofendidos com a postura crítica do filósofo, pois parecem concordar com o teatro que praticam. E o filósofo os chama de "servidores da palavra", pontua negativamente a representação pautada pela identificação, bem como o efeito catártico percebido no espectador vizinho, traços esses condizentes com uma arte dramática de matriz aristotélica.

Os princípios da arte dramática clássica estão traçados na "Poética" de Artistóteles (1966), dentre os quais, a mimesis, como atitude fundamental: "Poesia é imitação" (Aristóteles, 1966, p.241); a verossimilhança: “[...] não é ofício do poeta narrar o que aconteceu; é, sim, o de representar o que poderia acontecer, quer dizer o que é possível segundo a verossimiIhança e a necessidade [...]" (Aristóteles, 1966, p.249); e os efeitos catárticos, que constam da definição de tragédia:

É, pois, a tragédia imitação de uma ação de caráter elevado, completa e de certa extensão, em linguagem ornamentada e com as várias espécies de ornamentos distribuídos pelas diversas partes do drama, imitação que se efetua não por narrativa, mas me- 
diante atores, e que, suscitando 'terror e piedade, tem por efeito a purificação dessas emoções. (Aristóteles, 1966 p. 28)

Pelos princípios da verossimilhança e da necessidade a obra alcança a coerência interna, passando a fazer sentido por si só, como um produto autônomo desvinculado da natureza. A obra supõe a imitação, mas a sequência de ações mostradas precisa ser encadeada como se realidade fosse (o que "poderia ter acontecido"), sem visar o realismo e sem compromisso com o deveras acontecido, de modo que cada uma suceda necessariamente a antecessora, com vistas a alcançar essa autonomia de algo completo em si mesmo.

Roubine (2003, p.15) destaca a ausência de clareza de Aristóteles no que diz respeito às definições de verossímil e necessário, recorrendo a outras obras para elucidá-las. Segundo o autor, "O verossímil procede da experiência comum. É o que se produz commais frequência (Retórica) e, portanto, o que corresponde ao horizonte de expectativa do espectador."

A mimesis visa à catarse. A catarse é o "efeito" a ser provocado com a representação, consistindo na purificação dos sentimentos através das emoções, do terror e piedade que são despertados no espectador. O papel da arte não seria a mera produção de imagens da realidade, mas sim a produção de efeitos com essas imagens (realização da experiência teatral). Há muita discussão a respeito do sentido da catarse. Alguns autores concebem em seus efeitos a "clarificação intelectual" (Pereira, 2004).

As imagens produzidas representam a realidade (natureza) que miram. $E$ os efeitos desencadeados decorrem, segundo Aristóteles, do (re)conhecimento pelo espectador da vida representada: “(...) tal é o motivo por que se deleitam perante as imagens: olhando-as, aprendem e discorrem sobre o que seja cada uma delas, e dirão, por exemplo, 'esse é tal'" (Aristóteles, 1966, p. 243). A mimesis praticada e observada seria assim um ato de conhecimento (Lima, 2008). O que deleita é reconhecer a vida na imagem.

Para a produção de efeitos, também é indispensável o ato de identificação, ou empatia do espectador com o que é representado no palco. A identificação supõe a imitação e a verossimilhança. Identificar-se significa aproximar-se e enquadrar-se naqueles contornos mostrados, supondo assim uma possibilidade de modelação dos comportamentos humanos. Trata-se de uma atitude passiva, o espectador se deixa conduzir.

Segundo Brecht, em síntese,

[...] a representação e a fábula do teatro aristotélico não se destinam a dar retratos de processos da vida, mas sim a conseguir a experiência teatral (com certos efeitos de catarse) inteiramente determinada. São, no entanto, necessárias ações que façam lembrar a vida real, e estas devem ser suficientemente prováveis para que se crie a ilusão, sem a qual a identificação não se consegue. No entanto não é de modo algum necessário que, por exemplo, também a causalidade dos processos se evidencie; é de todo suficiente que não tenha de ser posta em dúvida. (Brecht, 1999, p. 13)

O teatro proposto pelo autor de $A$ compra do latão, em outro sentido, pesquisa a possibilidade de mostrar a realidade, de tomar como tarefa da arte não a produção de efeitos predeterminados, mas sim a produção de retratos dos processos vividos pelas pessoas, com o destaque de sua causalidade. $O$ autor entende que a representação da realidade deixa de ser 
um meio, manipulável e adaptável, destinado à produção da catarse, para se tornar o objeto da prática artística (Brecht, 1999, p. 14).

A questão é agora saber se é de todo impossível fazer da retração dos processos reais a tarefa da arte, e assim fazer da atitude crítica do espectador face aos processos reais uma atitude adequada à arte. (Brecht, 1999, p. 14)

Para fomentar esse novo modo de fazer artístico, o autor entende que o ato de identificação deveria ser mitigado em favor do efeito $\mathrm{V}$ (Verfremdungsefekt), efeito de distanciamento ou estranhamento.

No novo exercício da arte, a identificação perderia sua posição dominante. Por outro lado, seria agora criado o efeito de distanciação (efeito V), que é igualmente um efeito artístico conducente a uma experiência teatral. Consiste na retratação dos processos da vida real no palco de forma tal que a sua causalidade seja particularmente evidenciada e envolva o espectador. (Brecht, 1999, p. 14)

A atitude que fomenta a identificação é a de tornar habitual o acontecimento particular. Pelo efeito de distanciamento, torna-se particular o acontecimento habitual. O desafio é de contrastar o acontecimento com outros, destacando assim o que o torna diferente.

As emoções decorreriam do envolvimento do espectador com a realidade propriamente dita. A representação poderia sim deslocar o espectador, mas não em direção à "realidade da cena", e sim para fora do teatro, para as relações e processos do cotidiano de cada um.

Toda a força dessa forma de representação nasce continuamente da comparação com a realidade, ou seja ela dirige o olhar permanentemente para a causalidade dos processos representados. (Brecht, 1999, p. 16)
Os atores, ao interpretar a personagem, e o espectador, ao assistir ao ator, não se deixam conduzir pela representação. Eles (re)conectam-se constantemente com a vida.

\section{Um teatro pós-naturalista}

Brecht também dialoga criticamente com o Naturalismo, que parecia pretender se aproximar da vida, em crítica ao princípio da verossimilhança aristotélico, com o aprimoramento das descrições. Mas o que promoveu foi o aprimoramento da ilusão de se estar perante a realidade, sem desconsiderar a importância das descrições. A realidade mostrada é, na verdade, um olhar sobre uma realidade.

DRAMATURGISTA. As representações naturalistas despertavam a ilusão que se estava em um sítio real.

ACTOR. Olhando para dentro de um quarto, os espectadores pensavam sentir o cheiro dos cereais por trás da casa, olhando para o interior de um barco pensavam sentir a força da tempestade.

DRAMATURGISTA. Que se tratava somente de uma ilusão era mais evidente nas peças naturalistas do que nas encenações naturalistas. É claro que os autores das peças arranjavam os acontecimentos tão afincadamente com os não naturalistas. Combinavam, deixavam de fora, arranjavam encontros de pessoas em lugares improváveis, generalizavam acontecimentos, pormenorizavam outros, etc. Paravam quando a ilusão de que se estava a lidar com a realidade corria perigo de ser ferida.

ACTOR. Queres dizer que se trata meramente de uma diferença gradual, de representações mais ou menos realistas? Mas a diferença gradual é decisiva.

DRAMATURGISTA. Penso que se trata de uma diferença no grau da ilusão de se estar perante a realidade. $\mathrm{E}$ acho que é mais proveitoso sacrificar esta 
ilusão, quando esta pode ser trocada por uma representação que dá mais da própria realidade.

ACTOR. Uma representação que arranja, combina, deixa de lado, contrai sem se preocupar com a manutenção da ilusão de se estar perante a realidade?

FILÓSOFO. Bacon diz: 'A natureza revela-se mais quando é acossada pela arte do que quando é deixada a si própria'.

ACTOR. Já devem ter percebido que então já só se está perante as opiniões dos autores de peças sobre a natureza, e não perante a natureza?

DRAMATURGISTA. Já deves ter percebido que nas peças naturalistas só se estava perante as opiniões dos autores das peças. A primeira dramaturgia naturalista (dos Hauptmann, Ibsen, Tolstoi, Strindberg) foi acusada justamente de ser uma arte tendenciosa.

ACTOR. É este intelectualismo que corrói tudo. O teatro como escola infantil! Última atração: o salto quântico! Acrobacia cerebral (Brecht, 1999, p. $55)$.

O realismo moderno pode ser mais bem compreendido se confrontado com a estética anterior contra a qual insurge, a saber, aquela divulgada pelos autores neoclássicos. Roubine $(2003$, p. 100) discorre sobre esse desafio de romper com as convenções neoclássicas, assumido pelos autores franceses do século XIX, em favor de uma representação verídica da história. Segundo o autor, a intenção da estética neoclássica consistia em fazer "prevalecer o reino das convenções sobre o império da verdade", ou seja, considerava mais importante a fidelidade às normas do que o desenvolvimento de temas compatíveis com a época.

O realismo pretendia, com a "representação verídica da história", atingir a ilusão teatral. Entendia-se que seria necessário romper com as convenções aristotélicas, das três unidades, por exemplo, para que fosse possível retratar os acontecimentos históricos e, assim, acom- panhar os interesses do público da época. Os espectadores queriam ver a história recente no palco, era esse o conteúdo que promoveria a identificação.

A crítica de Brecht desenvolve-se no sentido de apontar como o realismo naturalista, que critica a estética (neo)clássica, acaba por reproduzi-la, em seu fundamento aristotélico da identificação, como mecanismo que promove a ilusão. É a veracidade da cena que permite que os espectadores se identifiquem com os personagens. São os efeitos predeterminados que são relevantes. A maneira de representar serve às emoções que se quer promover.

\section{A representação artística e a} realidade: mas qual realidade?

FILÓSOFO. Ora, então por que os imitam [os acontecimentos?

ACTOR. Para enchermos as pessoas de paixões e emoções, para as arrancarmos dos pequenos acontecimentos da sua vida quotidiana. Os acontecimentos são, por assim dizer, o suporte para o exercício da nossa arte, a prancha de salto que utilizamos.

FILÓSOFO. É isso mesmo.

DRAMATURGISTA. Não gosto nada do teu 'é isso mesmo'. Posso imaginar que dificilmente te contentarás com as paixões e emoções com as quais te querem encher. Não tinhas dito nada disto quando nos explicastes as razões para vires ao nosso teatro.

FILÓSOFO. Tenho de admitir isso. Peço desculpa. À vossa saúde!

DRAMATURGISTA. Eu, para dizer a verdade, prefiro brindar à tua saúde. Pois no fundo tratava-se de saber como o teatro te pode dar satisfação a ti, e não como nos pode satisfazer a nós.

ACTOR. Mas ele não vai querer dizer que tem alguma coisa contra quando fazemos mexer um pouco a sua mente preguiçosa? Bem, ele interessa-se mais por aquilo que nós imitamos, os acontecimentos, já sei, e menos por 
nós, mas como podemos fazer-lhe as imitações sem mobilizar os nossos sentimentos e as nossas paixões? Ele próprio iria simplesmente embora se fizéssemos uma representação fria. De resto não existe representação fria. Todos os acontecimentos nos emocionam, a não ser que fossemos insensíveis (Brecht, 1999, p. 85-86).

As personagens falam indistintamente em representação, reprodução da vida, imitação, mas destacando o papel mediador da arte. Nesse ponto, pode-se perceber uma falta de precisão conceitual acerca da diferenciação entre imitação e cópia, se confrontado o texto estudado com a análise de Bornheim (1992) em Brecht. "A estética do teatro", pois, segundo esse autor a imitação seria um conceito próprio da metafísica, incompatível com o teatro de Brecht.

O aristotelismo supõe a ideia de "imitação", conforme construída pelo platonismo, assim, a natureza seria uma imitação, ou uma cópia perfeita, da ideia, e a arte seria uma cópia da natureza, uma cópia da imitação, portanto. O platonismo pregava uma menor valia da arte, tendo em vista a distância em relação à ideia, tendo em vista que o artista, ao contrário do filósofo, não teria acesso à ideia, mas tão somente a uma imitação ou cópia dela, da qual faria apenas mais uma versão, o que não seria útil para o conhecimento.

Segundo Bornheim (1992, p. 351), a noção de referência muda do aristotelismo à cultura burguesa. A cultura burguesa descola-se progressivamente do mundo das ideias, admitindo o "mundo das cópias" como ponto de partida para o conhecimento. A realidade deixa de ser constituída por imitações de universais, as cópias ganham autonomia:

\begin{abstract}
Acabo de afirmar que o conceito de imitação entra em crise no decurso da cultura burguesa. $O$ asserto nos leva a uma nova problemática, a da cópia. Talvez seja até lícito afirmar que o feito maior da arte e da estética burguesas reside num duplo processo, através do qual, de um lado, leva-se à crise o conceito de imitação, e, de outro, reabilita-se aos poucos o de cópia. E por cópia entende-se precisamente aquele plano da realidade que a definia segundo os padrões do platonismo, com a decisiva diferença de que ela perde a sua conotação pejorativa e passa a assumir o estatuto da realidade propriamente dita. (Bornheim, 1992, p. 351-352).
\end{abstract}

Assim, o problema é que embora o mundo das ideias perca sua ascendência, a realidade continua a ser vista como se estivesse nele ancorada, com pretensões de unicidade. E a construção artística, por conseguinte, enquanto uma imitação desse "mundo das cópias".

Exatamente nesse ponto estaria a ilusão, dizer que a representação, o teatro, é tomado por realidade, implica dizer que existe uma realidade una, implica desconsiderar que todo olhar supõe um ponto de vista, e que, na verdade, qualquer "representação" oferece é uma cópia - imperfeita, e não uma imitação. Não se pode tomar um olhar por uma realidade unívoca, pois essa sequer existe. As representações artísticas da realidade são cópias de cópias, cada qual dependente dos sucessivos pontos de vistas incorporados.

Ao final da quarta noite, conclui o filósofo:

FILÓSOFO. Já falamos o suficiente sobre qual a utilidade da arte, como pode ser feita e de que depende a prática da arte, e também fizemos arte nestas quatro noites, de modo que podemos arriscar algumas afirmações prudentes de natureza abstracta acerca desta capacidade singular do homem, na esperança de que estas não sejam tomadas isoladamente e só por 
si, de maneira abstrata. Portanto, poderia talvez dizer-se que a arte é a habilidade de confeccionar reproduções da vida dos homens em comunidade, capazes de suscitar uma certa maneira de sentir, pensar e agir, diferentemente e mais intensamente do que aconteceria pela observação ou experiência a realidade representada. A partir da observação e da experiência da realidade o artista faz uma representação para ser observada e experimentada que reproduz a sua sensibilidade e o seu pensamento (Brecht, 1999, p. 68).

O ilusionismo faz passar a representação, que é uma construção artística, por realidade, como se existissem universais ou uma natureza una a serem imitados. Brecht quer que os espectadores percebam que não existe uma realidade dada por trás das construções que a arte oferece. A construção artística já incorpora o olhar do observador, e o produto oferecido contém um ponto de vista que precisa ser reconhecido.

O desafio do teatro épico é favorecer um acesso diferenciado ao assunto apresentado. Para tanto é preciso romper com a ilusão, movida pela identificação, de que a representação é uma cópia perfeita da realidade, ou que é a própria realidade. É preciso mostrar ao espectador algo com o que ele não se identifique passivamente, para que ele não se deixe conduzir pelo ponto de vista alheio, e sim olhe para si, para as particularidades e contingências que constituem o seu próprio ponto de vista.

Conclusões

Brecht supõe o teatro, e a arte, como um meio para o conhecimento. O autor constrói sua prática em crítica à poética aristotélica, pois entende que as iniciativas nela ancoradas produzem cenas enganosas, que fazem passar a representação por realidade, e promovem um conhecimento acrítico, pautado meramente na assimilação de conteúdos dados.

As representações que não deixem claro o tratamento que conferem ao assunto apresentado contribuem para a promoção de um falso conhecimento, pois o que se está a conhecer em qualquer representação não é a realidade, mas sim pontos de vista.

Brecht destaca o lugar do sujeito espectador, e a função do espetáculo em despertá-lo para olhar o mundo a partir do seu próprio ponto de vista.

\section{Referências}

ARISTÓTELES. Poética. Tradução, prefácio, introdução, comentário e apêndices de Eudoro de Souza. Porto Alegre: Globo, 1966.

BRECHT, Bertolt. A compra do latão. Tradução de Urs Zuber com a colaboração de Peggy Berndt. Lisboa: Vega, 1999.

. Pequeno Organon para o Teatro. Estudos sobre Teatro. Tradução de Fiama Pais Brandão. Rio de Janeiro: Nova Fronteira, 2005.

BORNHEIM, Gerd. Brecht. A estética do teatro. Rio de Janeiro: Graal, 1992.

HECHT, Werner; GELLERT, Inge. Notas e comentários sobre A compra do latão. In: BRECHT, Bertolt. A compra do latão. Tradução de Urs Zuber com a colaboração de Peggy Berndt. Lisboa: Vega, 1999.

LIMA, Paulo Butti. Arte e conhecimento em Aristóteles. In: Letras Clásicas, n. 12, p.169185, 2008. 
PEREIRA, Maria Helena da Rocha. Prefácio.

In: ARISTÓTELES. Poética. Lisboa: Fundação

Calouste Gulbenkian, 2004.

ROUBINE, Jean-Jacques. Introdução às grandes teorias do teatro. Tradução André Teles.

Rio de Janeiro: Jorge Zahar Editor, 2003.

Recebido: 15/05/2017

Aprovado: 25/08/2017 